\title{
Analysis of a Large Grounding System and Subsequent Field Test Validation Using the Fall of Potential Method
}

\author{
Huan Huang ${ }^{1}$, Hualin Liu ${ }^{1}$, Hong Luo ${ }^{1}$, Hao Du${ }^{1}$, Yi Xing ${ }^{1}$, Yexu Li ${ }^{2}$, \\ Farid P. Dawalibi ${ }^{2}$, Haijun Zhou ${ }^{2}$, Longhai Fu $^{2}$ \\ ${ }^{1}$ Guizhou Electric Power Test \& Research Institute, Guiyang, China \\ ${ }^{2}$ Safe Engineering Services \& technologies ltd, Blvd. Des Oiseaux, Laval, Québec, Canada \\ Email: info@sestech.com
}

Received April, 2013

\begin{abstract}
This paper examines various aspects of the design process and subsequent field test measurements of a large and complex substation grounding system. The study and measurements show that soil layering and lead interference can have a significant impact on the appropriate test location that yields the exact substation ground impedance. Applying a specific percentage rule such as the $61.8 \%$ rule for uniform soils to obtain the true ground impedance may lead to unacceptable errors for large grounding systems. This poses significant problems when attempting to validate a design based on raw test data that are interpreted using approximate methods to evaluate substation ground impedance, and determine ground potential rise (GPR), touch and step voltages. Advanced measurement methodologies and modern software packages were used to obtain and effectively analyze fall of potential test data, compute fault current distribution, and evaluate touch and step voltages for this large substation. Fault current distribution between the grounding system and other metallic paths were computed to determine the portion of fault current discharged in the grounding system. The performance of the grounding system, including its GPR and touch and step voltages, has been accurately computed and measured, taking into account the impedance of the steel material used of the ground conductors and circulating currents within the substation grounding system.
\end{abstract}

Keywords: Ground Resistance; Fall-of-Potential; Ground Impedance Measurement; Ground Potential Rise; Ground Potential Difference; Touch Voltage; Step Voltage; Steel Conductors

\section{Introduction}

Appropriate power system grounding is important for maintaining reliable operation of electric power systems, protecting equipment, and insuring the safety of public and personnel. A grounding system must be properly designed and its performance needs to be evaluated. Improper or inaccurate analysis can lead to significant expenses due directly to unnecessary over design or as a result of subsequent corrective measures caused by failures of the inadequate design. Most electrical engineers understand the importance of grounding system to discharge safely phase-to-ground faults into the surrounding soil.

Unfortunately, the complex and non-homogeneous nature of the soil, the intricate three-dimensional shape of the grounding system and topology of the entire power system network result in a very difficult task that requires appropriate specialized software packages and skilled professionals with adequate expertise in this field in order to account for the numerous factors that have to be considered during the design process and subsequent field measurement validation task.

It is often necessary to measure the ground impedance of a grounding system in order to validate a grounding analysis. The basic technique which is almost universally used for the measurement of grounding system impedance is known as the Fall-of-Potential method. The Fall-of-Potential method introduces two auxiliary electrodes, called return electrode and potential probe. When the return electrode is placed at a finite distance from the grounding system and the potential probe is driven into the earth at a specific location(the so-called "exact potential probe location") then an accurate measurement of the ground impedance is obtained.

For uniform soils and large distances between the grounding system and the return electrode, it is well known that the exact potential probe location follows the $61.8 \%$ rule, i.e., the exact location for the potential probe is $r=0.618 \mathrm{D}$, where $\mathrm{r}$ and $\mathrm{D}$ are the distances from the center of the grounding system to the potential probe and to the current electrode, respectively. It is important to understand that the $61.8 \%$ rule is based on the 
assumption that the soil is uniform and that the grounding electrode is small or hemispherical and that the potential probe and current electrode are also hemispherical or small.

For two-layer soils, a classical paper [3] has shown that the exact locations can vary from values close to $50 \%$ to values exceeding $90 \%$ depending on the nature of the two-layer soil structure and thickness of the top layer. This finding was included in Guide IEEE 81 -1983 [15] and was mysteriously removed in the 2001 edition before being reintroduced in the 2013 edition! In other words, the exact location of the potential probe is well defined for some ideal cases, such as hemispherical or small grounding electrodes buried in uniform or layered soils [1-6] but must be evaluated adequately when the separation distances are not large enough. In such cases, a value read at $61.8 \%$ may lead to significant errors on the measured ground impedance. The exact potential probe position must therefore be determined each time, using appropriate computer simulations.

Many grounding systems in China and several other countries are made of steel, which has higher permeability and lower conductivity than copper [7-11]. This raises some unique issues, particularly if the substation size is large and the soil resistivity is low. In a conventional grounding analysis approach, a grounding system is generally assumed as an equipotent structure. This would be inaccurate for most cases where steel grounding systems are used. In fact, the ground impedance of the grounding system has a significant inductive component, which is not taken into account by classical grounding analysis methods.

The analysis of the grounding system of an existing $500 \mathrm{kV}$ large substation is summarized in this paper. The substation includes $500 \mathrm{kV}, 220 \mathrm{kV}$ and $35 \mathrm{kV}$ switchyards. Two500 kV and seven $220 \mathrm{kV}$ transmission lines enter the substation.

Figure 1 is a plan view of the substation grounding system. The ground conductors are buried at a depth of $0.8 \mathrm{~m}$ and are made of $\mathrm{L} 60 * 6 \mathrm{~mm}$ steel conductors. A number of ground rods are installed at various locations of the grid. They are $2.5 \mathrm{~m}$ long and are made of $\mathrm{L} 60 * 3.5$ mm steel conductors.

Figure 2 is a plan view of the substation grounding system and the electrical network connected to it. Figure 2 also provides the soil resistivity measurement locations: one is inside the substation while another one is outside the substation. Figure 3 represents the multiphase circuit for a single-line-to-ground fault in the $220 \mathrm{kV}$ substation yard. It shows the equivalent circuit of the computer model used.

Figure 4 shows a typical cross section of all the transmission line towers modeled. A tower resistance of 15 or 20 ohms was used depending on the type of tower structure grounds.

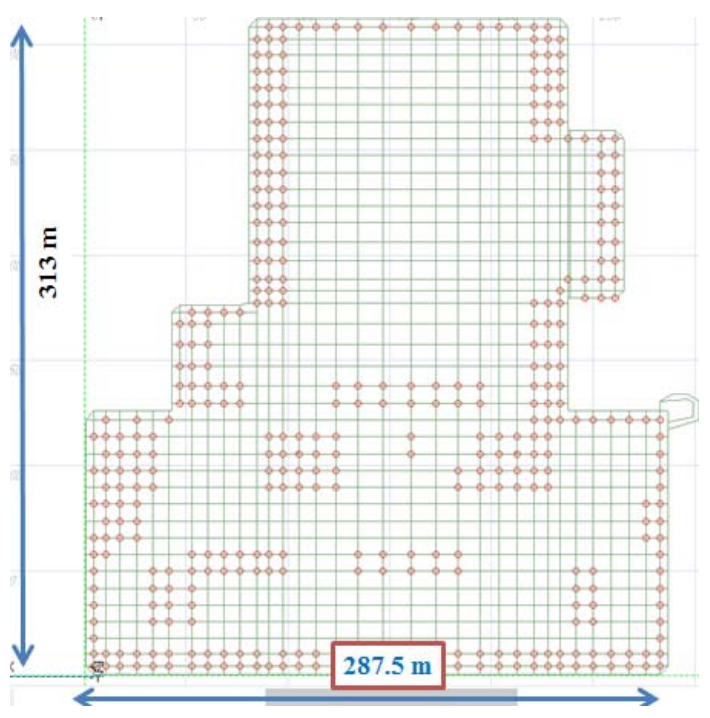

Figure 1. Plan view of the grounding system.

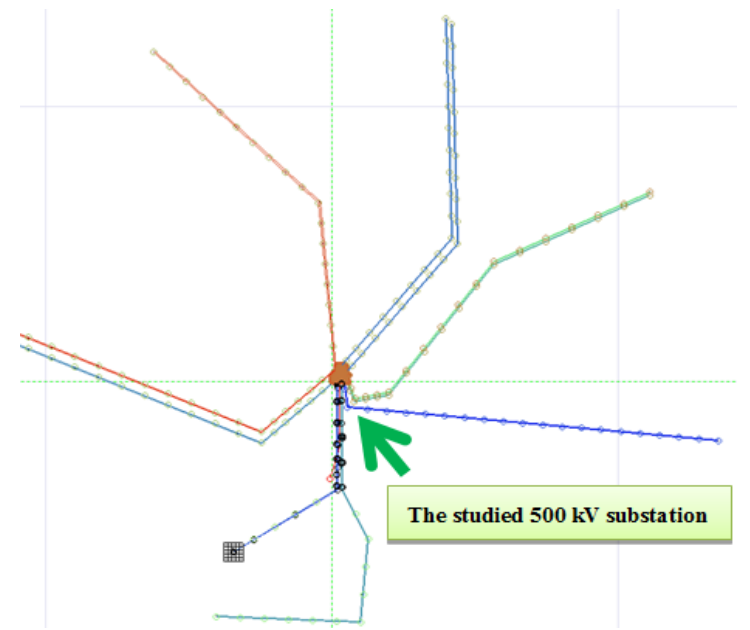

Figure 2. Plan view of the grounding system and the network connected to it.

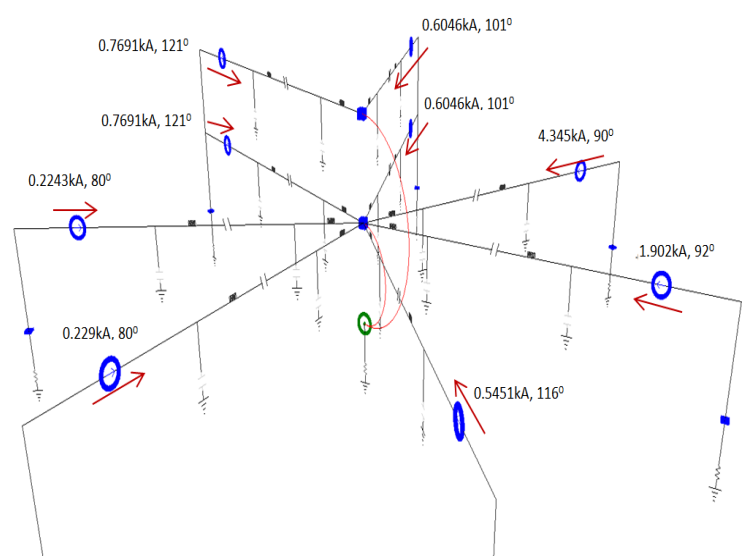

Figure 3. Simplified circuit model for fault current split calculations. 


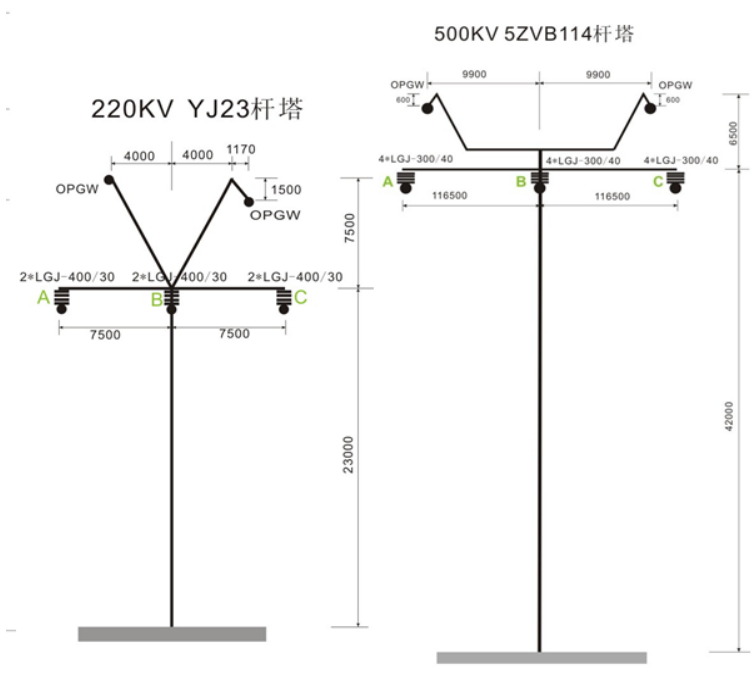

Figure 4. Typical cross section of the transimmsiosn lines.

To evaluate the grounding performance of the large system ground network, the following steps were carried out: 1) Soil resistivity and grid impedance measurements and interpretation; 2) Fault current split calculations; 3) Grounding system performance analysis.

This paper is not intended to report detailed grounding design issues and results but rather to highlight the various challenges encountered and their ramifications, if these challenges are ignored or if simplifying assumptions are made in place of a detailed grounding analysis. The results presented in this paper provide useful insight and information for accurately measuring the ground impedance of large grounding systems, for interpreting the measurements and for evaluating safety in the station. The analysis and the discussions can be used as a reference guide to study large grounding systems.

\section{Resistivity Measurements and Interpretation}

Soil resistivity measurements were made along two traverses at the substation site, using the Wenner four-pin method. Measurements along the short traverse inside the substation were carried out in order to obtain shallow depth resistivities at the project site. Measurements along one long traverse outside the substation were carried out in order to obtain soil resistivities at larger depths.

The measured soil resistivity data were interpreted using the RESAP computation module of the CDEGS software package [12]. Based on the principle that short traverse measurements determine shallow depth soil resistivity and large spacing measurements determine deep soil resistivity, a three-layer soil model was constructed, which is representative of the soil structures at the site and is expected to be conservative for the grounding analysis. The selected soil model is shown in Table $\mathbf{1 .}$

\section{Grounding Impedance Measurement and Interpretation}

To evaluate the performance of a substation grounding system, the ground impedance of the grounding system must be obtained either by measurement or by computation with appropriate soil resistivity measurements. Incorrect ground impedance will lead to incorrect fault current computation, therefore affecting the results of the analysis. Ideally, the ground impedance should be computed and then validated by measurement.

For this practical case study, due to the dense transmission line area and the expected low impedance measurement, a high current test unit was used. According to IEEE 81.2, it is recommended that the current probe has a minimum length of 6.5 times the diagonal of the substation. The substation is surrounded by difficult terrains. Fortunately, a small road was available along the west side of the substation. Therefore, the fall of potential test that followed this road was used to perform the measurements. Figures 5 and $\mathbf{6}$ illustrate the test setup which was carried out for multiple frequencies of 47, 46, 53 and $54 \mathrm{~Hz}$ for each test point. The fall of potential test results are summarized in Figure 7 (red dots).

The next stage of the analysis was to model the fall of potential test, using the soil model developed from measured soil resistivity data (shown in Table 1). The first challenge was to determine how much of the overall transmission line grounding network is really influencing

Table 1. Selected soil model.

\begin{tabular}{ccc}
\hline Layer & Resistivity $(\boldsymbol{\Omega}-\mathbf{m})$ & Thickness $(\mathbf{m})$ \\
\hline Top & 320 & 0.35 \\
Central & 65 & 2.0 \\
Bottom & 420 & infinite \\
\hline
\end{tabular}

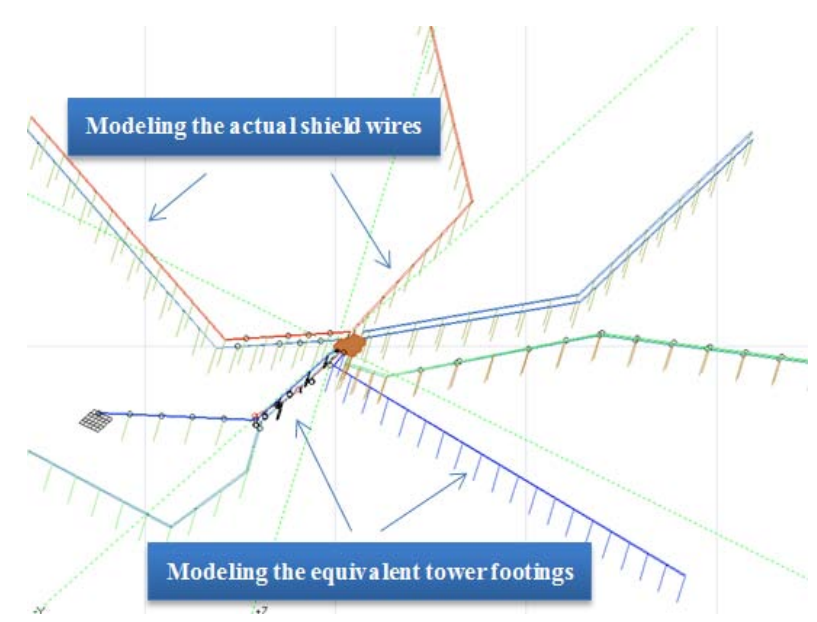

Figure 5. Fall of potential test setup (complete model). 


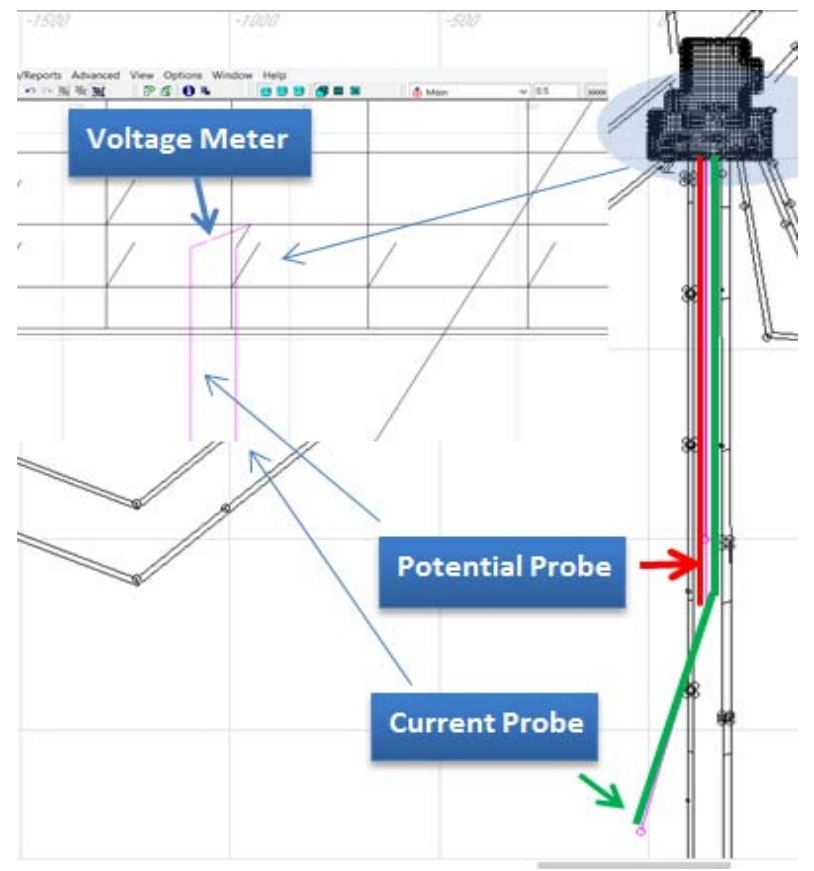

Figure 6. Fall of potential test setup(zoomed model).

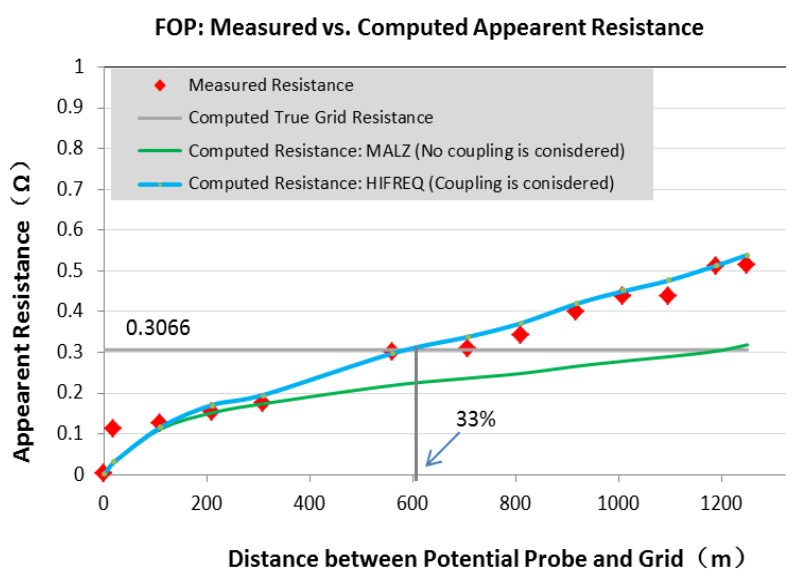

Figure 7. Computed and measured appearent resistance.

the GPR of the substation. After building an accurate model of 5-10 km shield wires, including all tower footing structures and substation grounding grids corresponding to the real network in the area, the fall of potential results were computed. A sketch of the model is shown in Figure 5. In this model, no current or potential leads were modeled. The MALZ computation module of CDGES was used. This module takes into account the voltage drops along a grounding system and is therefore capable of modeling large grounding systems with steel conductors. It means that the developed model accounts correctly for the conductive coupling, but does not account for inductive effects between the measuring leads and other paralleling conductors.

The results of this fall of potential simulation are shown in Figure 7(green curve). As it can be seen, a significant discrepancy exists between the measured curve and the computed curve. The first common sense reaction may be to conclude that the soil model was incorrect. However, after modeling the test leads (Figures $\mathbf{5}$ and $\mathbf{6}$ ) and using the HIFREQ computation module of CDEGS which accounts for all relevant electromagnetic effects, i.e., for conductive, inductive as well as capacitive coupling effects, one can notice that the resulting theoretical fall of potential test results, compared with the measured results (shown in Figure 7 as a blue curve and red dots), agree with each other very well. Conductive coupling arises as a result of the proximity of current circuit return ground grids and nearby buried structures, such as tower footing, connected to the ground grid. Inductive coupling is a result of the test leads being mutually coupled with buried structures that are connected to the substation ground grid. Capacitive coupling is due to the capacitance between buried and above ground conductors).

The computed true grounding impedance at $50 \mathrm{~Hz}$ is $0.3066 \angle 13.55^{\circ} \Omega$ for the complete network and $0.6349 \angle$ $1.21^{0} \Omega$ for the substation grid alone. It is clear that the exact potential probe location for the entire network impedance, energized at $50 \mathrm{~Hz}$ case, is at $33 \%$ of the distance between the injection point and the return electrode, which is far from the suggested rule of $61.8 \%$. A value of $0.51 \Omega$ is obtained for the ground impedance of the entire system if the $61.8 \%$ reading is used, an error ofabout $66 \%$. This is because a) the return electrode is not located far enough from the grounding grid, compared to the measured grounding system dimension (i.e., the complete network); b) the soil model is non-uniform; c) the test leads were close and parallel to each other $(\sim 4 \mathrm{~m})$.

The above analysis has shown how to use a judicious operating frequency to measure the grounding impedance of a substation grid that is connected to other grounding electrodes through shield wires and interpret the data correctly. This is an important issue when dealing with large substation grounding systems.

\section{Fault Current Split Calculations}

The objective of the fault current split calculations is to obtain the earth current (current discharged by the grounding system to earth). Under most conditions, the total fault current doesn't discharge entirely in the substation grounding system. Part of the fault current, which does not contribute to the GPR of the grid, will return to remote source terminals and to transformer neutrals through shield wires, neutral wires or conductors of the grid.

It is well known that the GPR and the touch and step voltages associated with the grounding network are directly proportional to the magnitude of the fault current component discharged directly into the soil by the 
grounding network. It is therefore important to determine how much of the fault current returns to remote sources via overhead ground wires and neutral wires of the transmission lines and distribution lines connected to the substation.

Computer simulations have been performed using the Right-Of-Way software package described in [12] based on the circuit model shown in Figure 3 and on the computed ground impedance of the substation in the soil shown in Table 1. A circuit model representing the scenario of a $220 \mathrm{kV}$ single-line-to-ground fault at the power plant is shown in Figure 3. Figure $\mathbf{3}$ also shows the fault current contributions from all sources; Figure 8 shows the distribution of the fault current along the transmission line overhead ground wires for a $220 \mathrm{kV}$ single-phaseto-ground fault. Table 2 shows the results of fault current distribution calculation. Note that the local source contribution from the $500 \mathrm{kV} / 220 \mathrm{kV}$ step-up transformers in the substation is estimated to be about $8 \mathrm{kA}$, as shown in Table 2. This current was not modeled in the circuit current split calculations because it circulates [13] between the fault location and the step-up transformers via neutral and ground conductors. However, this circulating current was included in the grounding system model as it should.

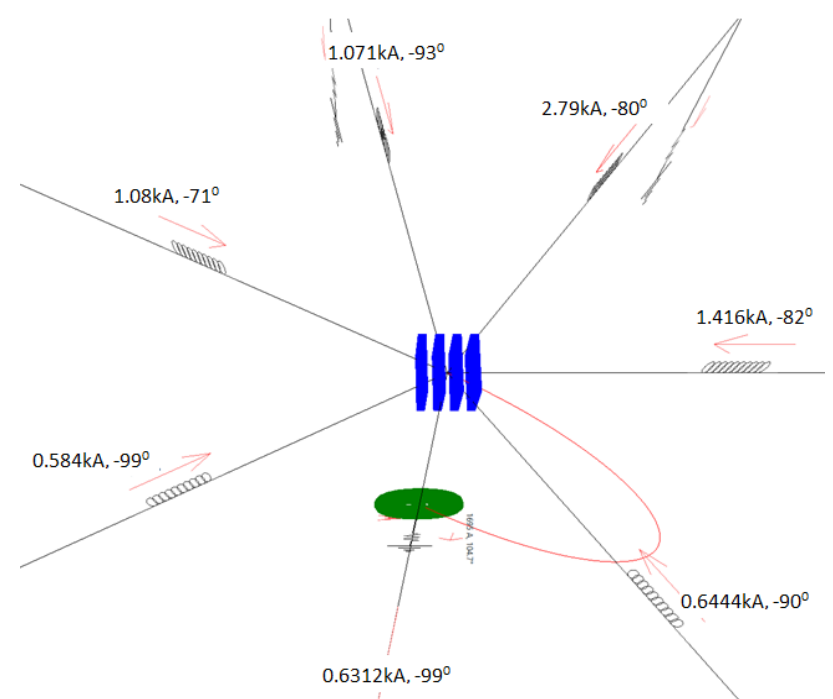

Figure 8. Computed fault current in the power line overhead ground wires.

Table 2. Fault current split calculation results.

\begin{tabular}{cc}
\hline Remote contribution & $9.8 \angle-97.1^{\circ} \mathrm{kA}$ \\
\hline Local contribution (circulating current) & $8.0 \angle-90.0^{\circ} \mathrm{kA}$ \\
Total fault current & $17.77 \angle-93.9^{\circ} \mathrm{kA}$ \\
Current returning via $\mathrm{OHGW}$ & $8.14 \angle 95.5^{\circ} \mathrm{kA}$ \\
Earth current discharged in grid & $1.78 \angle 105^{\circ} \mathrm{kA}$ \\
\hline
\end{tabular}

\section{Grounding System Performance Analysis}

GPR, touch and step voltages are important quantities when a substation is assessed. The calculation of GPR, touch and step voltages was carried out using the MALZ computation module[12], which takes into account attenuation or voltage drop along conductors in a grounding system, avoiding therefore the incorrect assumption that a grounding grid is equipotential.

In this study case, we have a $500 \mathrm{kV}$ substation at different voltage levels, i.e., $500 \mathrm{kV}, 220 \mathrm{kV}$ and $35 \mathrm{kV}$, fed by several power source terminals at $500 \mathrm{kV}$ and 220 $\mathrm{kV}$. When a single-phase-to-ground fault occurs on a 220 $\mathrm{kV}$ bus, the $500 \mathrm{kV}$ side will supply fault currents through the $500 \mathrm{kV}$ transformers; part of the fault current will return to the transformer neutral through the grid conductors (circulating current between the fault location and the transformer neutral point).

Similarly, the fault current is injected at the fault location and a portion of it returns to the remote source through the shield wire connected to the grid (circulating between the fault location and the shield wire connecting point). Because of the low impedance path provided by the ground conductors, only a negligible small amount of this current leaks out from the ground conductors to earth. As a result, circulating currents do not affect significantly the average grid GPR but may distort its shape significantly. However, for a large substation, the distance between the fault location and the transformer neutral point or the shield wire connecting connection point can be quite large. As a result, high potential differences, due to this large circulating current, may exist within the grounding grid. In other words, the circulating current contributes to the ground potential differences (GPD) between various locations of the grid and results in higher touch and step voltages, especially for a large grounding system and low soil resistivity soil environments.

Obviously, ignoring transformer and shield or neutral wirescirculating currents in a grounding system study can lead to inaccurate designs leading to unsafe situations.

A computer model was built for the grounding system. Figure 9 shows the model considering all current sources, including circulating currents.

The maximum acceptable touch and step voltages are indicated in Table 3 that are calculated based on the following criteria:

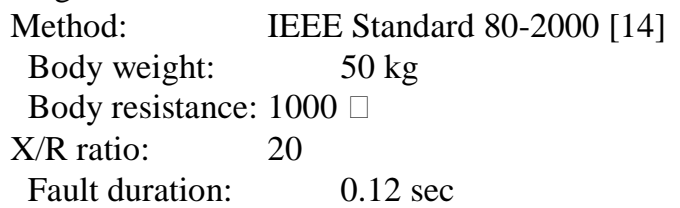

All accessible areas inside and outside the substation, for all possible soil surface covering materials: native soil, crushed rock or asphalt (even very low resistivity materials), had acceptable touch and step voltages under 
all fault scenarios, i.e., $500 \mathrm{kV}$ or $220 \mathrm{kV}$ faults, assuming computed and measured tower resistances, and at different fault locations.

Figure 10 shows typical ground potential rises (GPRs) along the grid conductors for a $220 \mathrm{kV}$ fault. Figure 11 and Figure 12 show typical touch and step voltages inside and outside the substation, respectively. Figure 13 provides example of soil potentials.

\section{Conclusions}

The performance of a large substation grounding system has been analyzed using modern techniques. A nonuniform soil model has been derived based on soil resistivity measurements, and it has been applied throughout the study.

The paper shows that by following the IEEE 81.2 recommended methodologies for fall of potential testing, significant errors are introduced for a large grounding system connected to an extended network, due to conductive and inductive effects. It was shown that matching the fall of potential test data with a detailed computer model using an appropriate software package can significantly change the computed ground potential rise, touch and step voltages in a substation.

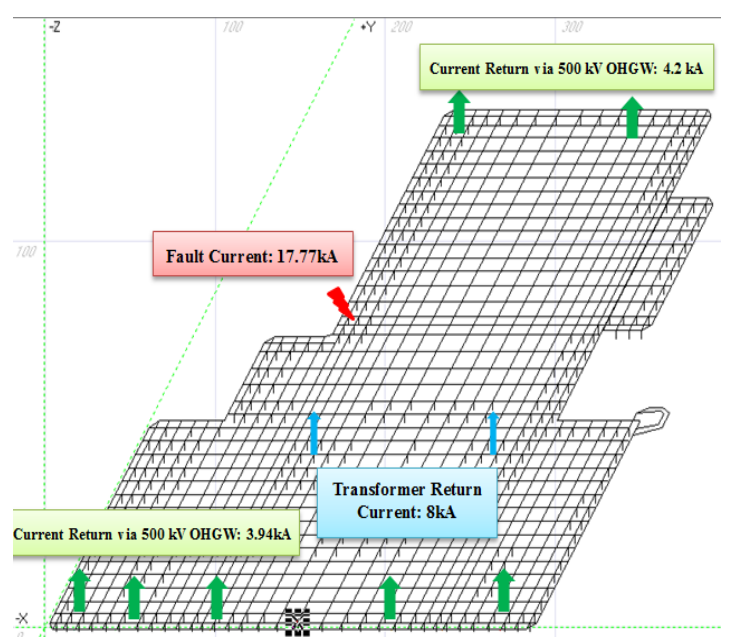

Fiugre 9. Ground network model for evaluating safety at the substation.

Table 3. Safety Limits.

\begin{tabular}{cccc}
\hline \multicolumn{2}{c}{ Surface } & \multicolumn{2}{c}{ Maximum Acceptable } \\
\hline Soil & $\begin{array}{c}\text { Resistivity } \\
(\square-\mathrm{m})\end{array}$ & $\begin{array}{c}\text { Touch } \\
\text { Voltage (V) }\end{array}$ & $\begin{array}{c}\text { Step } \\
\text { Voltage }(\mathrm{V})\end{array}$ \\
\hline Very Low & 0 & 272 & 272 \\
Native & 320 & 407 & 815 \\
Crushed Rock & 2000 & 973 & 3078 \\
Wet Concrete & 30 & 282 & 323 \\
Asphalt & 10,000 & 4518 & 17257 \\
\hline
\end{tabular}

Figure 10. Conductor GPR (Ground Potential Rise).

Figure 11. Touch voltages at the substation.

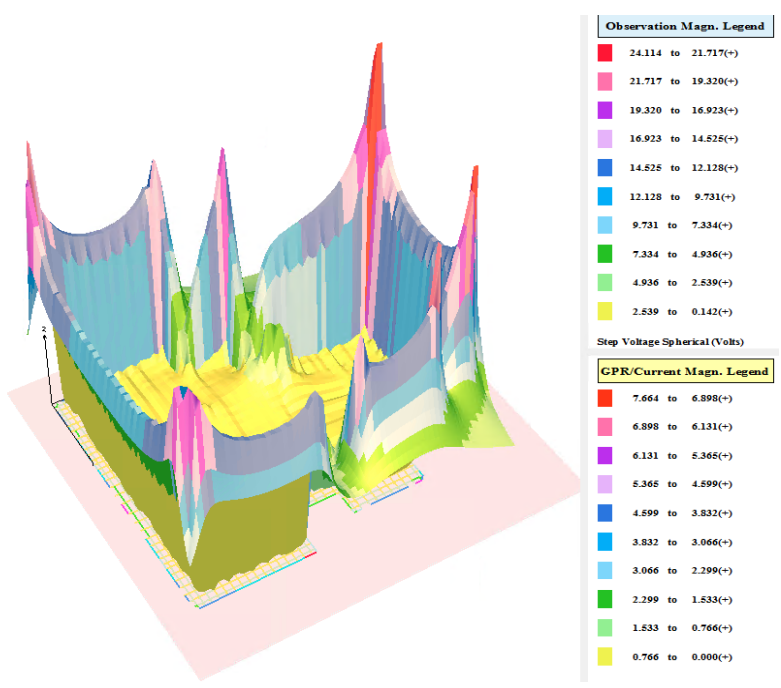

Figure 12. Step voltages inside and outside the substation. 


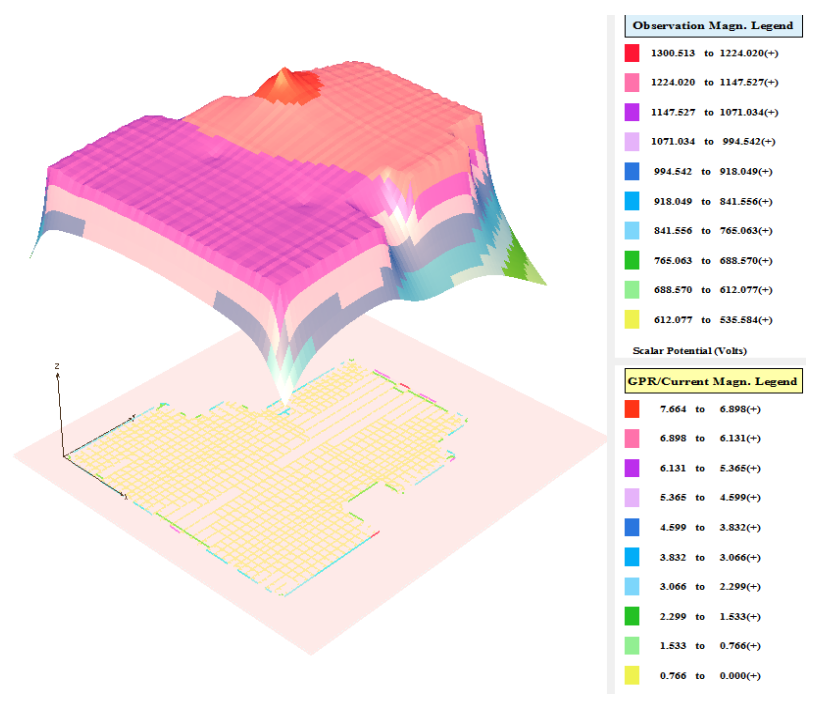

Figure 13. Soil Potentials inside and outside the substation.

A complete circuit model of the overhead transmission line network has been built in order to determine the current distribution during a single-phase-to-ground fault. Therefore, current injected into the soil through the grid (which contributes to the GPR, touch and step voltages) was obtained. Due to the large size of the grounding system and to the fact that the grid is made of steel ground conductors, the conventional approach used in grounding analysis (equipotential grounding system) can lead to wrong results. Therefore, adequate methods taking into account voltage drops along the grid conductors and circulating currents within the substation must and have been used to compute the grid GPR, touch and step voltages.

The procedures presented in this paper can be used as a guide when carrying out grounding analysis of a large power substation.

\section{Acknowledgements}

The authors wish to thank Mr. J. L. Chagas of SES for his review and comments on the paper manuscript.

\section{REFERENCES}

[1] F. P. Dawalibi and D. Mukhekar, "Resistance Measurement of Large Grounding Systems," IEEE Transactions on Power Apparatus and Systems, Vol. PAS-98, No. 6, 1979, pp. 2348-2354. doi:10.1109/TPAS.1979.319434

[2] J. Ma and F. P. Dawalibi, "Effects of Inductive Coupling between Leads in Ground Impedance Measurement Using Fall-of-Potential Method”, in Proc. IEEE/Power Eng. Soc.
Trans. Dis. Conf. Expo., New Orleans, LA, Apr. 11-16, 1999, pp. 266-271.

[3] F. P. Dawalibi and D. Mukhekar, "Ground Electrode Resistance Measurement in Nonuniform Soils," IEEE Transactions, Vol. PAS-93, No. 1, Jan. 1974, pp. 109-116.

[4] J. Ma, F. P. Dawalibi and W. Ruan, "Ground Impedance Measurement and Interpretation in Various Soil Structures,” IEEE/PES Winter Meeting 2000, Singapore, Jan. 23-27, 2000.

[5] J. Ma and F. P. Dawalibi, "Extended Analysis of Ground Impedance Measurement Using the Fall-of-Potential Method," IEEE Transactions on PWRD, Vol. 17, No. 4.

[6] Y. Li, J. Ma and F. P. Dawalibi, "Impedance Measurement of Large Grounding Systems Using the Fall-of-potential Method," Proceedings of the Third IASTED International Conference on Power and Energy Systems, EuroPES 2003, Marbella, Spain, Sept. 3-5, 2003, pp. 701-706.

[7] G. Yu, J. Ma and F. P. Dawalibi, "Effect of Soil Structures on Grounding Systems Consisting of Steel Conductors," Proceedings of the International Conference on Electrical Engineering (ICEE'2001), Xian, China, July 22-26, 2001.

[8] Y. Li, J. Ma and F. P. Dawalibi, "Power Grounding Safety: Copper Grounding Systems vs. Steel Grounding Systems," International Conference on Power System Technology (POWERCON2006), Chongqing, China, October 22-26, 2006.

[9] Y. Li, F. Dawalibi, J. Ma and Y. Yang, “Analysis of A Steel Grounding System: A Practical Case Study,” The 15th Conference on Electric Power Supply Industry (CEPSI) Shanghai, China, October 18-22, 2004.

[10] J. Ma and F. P. Dawalibi, “Grounding System Design for a Large Power Plant,” The 4th IASTED Asian Conference on Power and Energy Systems (AsiaPES), Langkawi, Malaysia, April 2-4, 2008.

[11] J. Ma and F. P. Dawalibi, "Grounding Analysis of a Large Electric Power Station,” International Conference on Power System Technology (Powercon2006), Chongqing, China, October 22-26, 2006.

[12] CDEGS Software Package, Safe Engineering Services \& technologies ltd., Montreal, Quebec, Canada, 1991 2012.

[13] Y. Li and F. P. Dawalibi, "Practical and Realistic Considerations of Fault Current Analysis," Proceedings of the International Conference on Electrical Engineering (ICEE 2011), Hong Kong, July 10 - 14, 2011.

[14] Guide for Safety in AC Substation Grounding, IEEE Std. 80-2000.

[15] Guide for Measuring Earth Resistivity, Ground Impedance and Earth Surface Potentials of a Ground System, IEEE Std. 81-1983, IEEE. 